\title{
Potential Control of Postharvest Gray Mold of Pomegranate Fruits Caused by Botrytis Cinerea
}

\author{
Samar A. Allam ${ }^{1}$, Gabr A. Elkot ${ }^{2}$, Abdelnaser A. Elzaawely ${ }^{*}$ and \\ Hassan M. El-Zahaby ${ }^{1}$ \\ $1^{*}$ Department of Agricultural Botany, Faculty of Agriculture, Tanta University, Tanta, \\ and ${ }^{2}$ Department of Agricultural Botany, Faculty of Agriculture, Kafr Elsheikh \\ University, Kafr El Sheikh, Egypt.
}

\begin{abstract}
C RAY mold rot, caused by Botrytis cinerea, is one of the most economically significant postharvest diseases in pomegranate fruits. The aim of the current study is to evaluate Mangifera indica, Thymus vulgaris, Origanum majorana, Salix mucronata, Cinnamomum cassia and Zingiber officinale extracts and biocontrol agents for controlling gray mold disease on pomegranate. In vitro results showed that T. vulgaris (T.v), C. cassia (C.c) and Z. officinale (Z.o) extracts possessed highly significant antifungal activities as they completely inhibited the radial growth of $B$. cinerea at the concentrations of 30000,20000 and $30000 \mathrm{ppm}$, respectively. The combination of the aforementioned plant extracts and fungicide Flusilazole (Flu) overcomes the potency of Flu or the plant extracts alone specially C.c+Flu at the rate of $(2: 1 ; \mathrm{v} / \mathrm{v})$ since it inhibited the radial growth of $B$. cinerea with $89.6 \%$ inhibition compared to the control. The study also proved that using the aforementioned plant extracts alone or in combination with Flu as well as the bacterial antagonists (Bacillus subtilis or Pseudomonas fluorescens) significantly reduced the loss in fruit weight. Furthermore, they also prolonged the storage period of pomegranate fruits and maintained high-quality parameters including soluble solids content and titratable acidity after cold storage at $5 \pm 1^{\circ} \mathrm{C}$ and $90 \%$ RH. In conclusion, using fungicides in controlling pomegranate fruit rots can be reduced by using the aforementioned plant extracts, bacterial antagonists and by reducing the concentration of fungicide through combining the plant extracts with half or one-third of the fungicide recommended dose to maintain eco-system safety and human health.
\end{abstract}

Keywords: Pomegranate, Botrytis cinerea, Plant extracts, Antagonists, Flusilazole.

\section{Introduction}

Pomegranate Punica granatum L. (Punicaceae) is known as one of the oldest edible fruits. Since the time of the ancient Egyptians, the very old pomegranate tree was cultivated in Egypt (Mars, 2000). According to the statistic of Agriculture Directorates of Governorates in 2011 in Egypt, the total cultivated area with pomegranate was 10866.24 hectare with a total production of 89035 ton (El-Qurashi et al., 2017). Pomegranate cultivar "Wonderful" is known for its sweet taste, plentiful juice and health benefits that may help with heart disease, cancer and problems associated with aging. It is loaded with antioxidants, vitamins, potassium, folic acid and iron (Thomidis, 2014). Pomegranates are predisposed to attack from numerous pathogens at pre- and/or postharvest stage, which has a major impact on fruit quality and storage life. The most recognized fungal pathogens of pomegranate include Botrytis cinerea, Aspergillus niger, Penicillium spp., Alternaria spp., Trichoderma spp., Colletotrichum gloeosporioides, Pestalotia brevista and Pilidiella granati and the affected fruits are non-marketable (Teksur et al., 2014).

Botrytis cinerea, the causal agent of gray mold, which is usually the most economically significant postharvest pathogen in pomegranate (Palou and Del Rio, 2007). Based on the growing season, it can destroy $30-50 \%$ of the pomegranate fruits during cold storage (Teksur et al., 2014).

Currently, the use of synthetic chemical fungicides is the primary means to control postharvest diseases. However, there is a necessity to develop effective, safe, compatible,

*Corresponding author email: elzaawely@agr.tanta.edu.eg

DOI : $10.21608 /$ JENVBS.2017.1822.1011

C2017 National Information and Documentaion Center (NIDOC) 
and economical alternative techniques to control postharvest gray mold of vegetables and fruits (Wu et al., 2016). Satisfactory results have been reported using bio-control or antagonistic microorganisms and natural compounds including various plant extracts (Fielding et al., 2015).

In this respect, the main goal of this study was to minimize the use of synthetic fungicides entirely or partially by natural ones.

\section{Materials and Methods}

Isolation and identification of the pathogens associated with rotted pomegranate fruits

Diseased pomegranate fruits showing rot symptoms were collected from orchards, wholesale and retail markets as well as refrigerators at El-Gharbia, Kafr El-Sheikh, El-Behira and Alexandria Governorates. The diseased specimens were used for the isolation of the causal pathogens according to the methods adopted by (Brown, 1924). The isolated fungi were purified by hyphal tip and/or single spore technique (Hansen, 1926), then kept in a refrigerator at $4{ }^{\circ} \mathrm{C}$, for further studies. The causal pathogens were identified according to their morphological characters using the description of (Ozcelik and Ozcelik, 1997).

\section{Pathogenicity test}

Apparently, healthy mature fruits of pomegranate cultivar "Wonderful" were selected and washed by dipping in tap water for $10 \mathrm{~min}$, then kept to dry at room temperature $\left(20-25^{\circ} \mathrm{C}\right)$. The fruits were surface-sterilized in $0.3 \%$ sodium hypochlorite for three min. Then washed several times in sterilized distilled water. Inoculation tests were performed by inserting the fungal inocula into holes ( $5 \mathrm{~mm}$ diameter and $4 \mathrm{~mm}$ deep) made into the fruits, using a cork borer. Inocula were taken from the growing margin of 9 days old PDA cultures of the tested fungi. After the inoculation, the holes were plugged with the removed pieces (El-Arosi, 1960). Each treatment consisted of three replicates with four fruits/replicate. Check treatment was similarly treated, but without fungal inoculation. The inoculated fruits were put in opened polyethylene bags, stored at $\left(22-24{ }^{\circ} \mathrm{C}\right)$ and $65 \%$ RH. Disease development of infection of the causal pathogens was estimated as diameter of the external rot (Moline and Locke, 1993).

In vitro control of $B$. cinerea on pomegranate fruits Plant material

Green, medium sized and healthy leaves of four plant species including Mangifera indica (mango; Family: Anacardiaceae), Thymus vulgaris (thyme; Family: Lamiaceae), Origanum majorana (oregano; Family: Lamiaceae) and Salix mucronata (Safsaf willow; Family: Salicaceae) were collected from the farm of Faculty of Agriculture, Tanta University. In addition, bark of Cinnamomum cassia (cinnamon; Family: Lauraceae) and mature rhizomes of Zingiber officinale (ginger; Family: Zingiberaceae) were purchased from local market. Samples were washed thoroughly with detergent to remove dust and were dried in an electric oven at $40^{\circ} \mathrm{C}$ for 4 days. Dried samples were separately powdered and kept in refrigerator until use.

\section{Preparation of plant extracts}

Ten $g$ dried powdered of each plant sample were separately extracted with aqueous methanol $80 \%(3 \times 100 \mathrm{ml})$ with $0.1 \% \mathrm{HCL}$ for 2 hours at 50 ${ }^{\circ} \mathrm{C}$ with stirring (Mujica et al., 2009). After cooling, different extracts were separately centrifuged at $4000 \mathrm{rpm}$ for $15 \mathrm{~min}$, then filtrated. The extraction procedure was repeated again with the residue. After centrifugation and filtration, all extracts were separately collected and dried at $35-40^{\circ} \mathrm{C}$ to give the dry crude extract. Subsequently, stock solution of each extract was prepared by dissolving the dried crude extract in sterilized distilled water and kept in the refrigerator until use.

\section{In vitro antifungal activity of plant extracts against $B$. cinerea}

Preliminary in vitro antifungal assays were performed with the plant extracts on PDA using the radial growth method against $B$. cinerea as described by Latha et al. (2009) to assist in the selection of the effective plant extracts for this study. PDA medium was prepared by autoclaving at $121^{\circ} \mathrm{C}$ and cooled to $45^{\circ} \mathrm{C}$. Afterwards, appropriate volume of each extract was added to PDA medium to get several concentrations, while sterilized distilled water was used as negative control. PDA medium was thoroughly mixed with plant extracts and the mixture was poured into sterilized $9 \mathrm{~cm}$-Petri plates and allowed to solidify. Three plates were used for each concentration as replicates. The plates were then inoculated with $5 \mathrm{~mm}$-disks of 7-day old culture of $B$. cinerea grown on PDA. The inoculated dishes were sealed with parafilm to avoid the evaporation of volatile compounds and incubated at $\left(23 \pm 2^{\circ} \mathrm{C}\right)$ until mycelial growth of pathogenic fungi covered the surface of medium in control treatment (after 5 days). The percent inhibition of radial growth 
of $B$. cinerea was calculated using the following equation (Latha et al., 2009):

$$
\text { Inhibition } \%=\frac{\mathrm{c}-\mathrm{t}}{\mathrm{c}} \times 100
$$

where, $\mathrm{C}$ : is the diameter of hyphal extension $(\mathrm{cm})$ of controls and, $\mathrm{T}$ : is the corresponding diameter of treatments.

The fungicide Flusilazole (trade name of PUNCH ${ }^{\circledR} 40$ EC) was purchased from Co., Kafr El-Zayat, Kafr El-Zayat, Egypt to be used in this study as a positive control.

In vitro determination of minimum inhibitory concentration (MIC) of plant extracts and Flusilazole

The plant extracts $C$. cassia, $T$. vulgaris, and $Z$. officinale exhibited the highest antifungal properties against radial growth of $B$. cinerea. To determine the MIC of the three aforementioned plant extracts and fungicide Flusilazole, serial concentrations were prepared by mixing appropriate volumes of each sample with PDA medium. The antifungal tests were evaluated as described above with three replicates. The MIC value was defined as the lowest sample concentration required for complete suppression of mycelial growth of the tested fungus (Latha et al., 2009).

In vitro antifungal potential of plant extracts, Flusilazole and their combinations against $B$. cinerea

Mixtures of fungicide Flusilazole and $C$. cassia, T. vulgaris and Z. officinale extracts (v/v) were tested against $B$. cinerea by using the radial growth method as described above (Latha et al., 2009). All the assays conducted with mixtures of the plant extracts and Flusilazole contained an increasing dose of the extracts and fungicide Flusilazole. Control contained sterilized distilled water without the compounds. The mixtures were applied at the rates of 1:1, 1:2 and 2:1 (v/ v) Flusilazole to plant extract, respectively. The antifungal tests were evaluated as described above with three replicates.

In vitro antagonistic effect of $B$. subtilis and $P$. fluorescens against certain fungal pathogens of pomegranate fruit

The antagonistic effect of B. subtilis and $P$. fluorescens against the causal pathogens of pomegranate fruit rots (B. cinerea, $P$. expansum,
A. alternate, A. niger and P. rubrum) was studied. These bioagents were previously isolated and identified by El-Kot and Hegazi (2008) and tested on petri dishes at laboratory conditions, using standardized test described by Ibrahim et al. (1987) as follows:

$$
\text { R.P.A }=\mathrm{Z} / \mathrm{C}
$$

where R.P.A = Relative power of antibiosis of bacterial antagonists against the major fungal pathogen of pomegranate fruits.

$\mathrm{Z}=$ Diameter of inhibition $(\mathrm{cm})$.

$\mathrm{C}=$ Diameter of spotted antagonistic isolate $(\mathrm{cm})$.

In vivo control of postharvest diseases of pomegranate fruits during cold storage at $5 \pm 1{ }^{\circ} \mathrm{C}$ and $90 \% \mathrm{RH}$

Pomegranate fruits cultivar "Wonderful" were purchased from private orchard in El-Alamein city, Matrouh governorate at maturity stage in 2015 and directly transported to the laboratory of the Department of Agricultural Botany, Faculty of Agriculture, Kafr El-Sheikh University. Fruits were harvested from similar trees. The selected trees were grown in sandy soil under drip irrigation system and planted at $2 \times 3 \mathrm{~m}$ apart.

Only sound fruits were picked up, then washed thoroughly with running water to remove any dirties, surface-sterilized with distilled water and air-dried. Afterwards, the fruits were treated with the following treatments:

1. C. cassia, Z. officinale and $T$. vulgaris at concentrations of 15000,17000 and 17000 ppm, respectively.

2. Mixture of each of the aforementioned plant extracts with fungicide Flusilazole at the rate 2 extract: 1 Flusilazole with concentration (100:50 ppm).

3. B. subtilis or P. fluorescens at $1 \times 10^{8} \mathrm{CFU} \mathrm{m}^{-1}$.

4. The fungicide Flusilazole at $150 \mathrm{ppm}$ was used as a positive control.

5. Treatment of pomegranate fruits with distilled water used as a negative control.

Fruits were floated in different sample solutions for $3 \mathrm{~min}$ and then air dried again. After that, they were put in polyethylene bags (previously disinfected with $70 \%$ ethanol and exposed to UV light for $20 \mathrm{~min}$ ) containing $2 \mathrm{~g}$ of potassium permanganate as ethylene adsorper then stored at $5 \pm 1{ }^{\circ} \mathrm{C}$ and $90 \% \mathrm{RH}$.The experimental design used at this study was randomized complete block design with three replicates in each treatment. 
Each replicate contained five fruits. Certain quality indices and physiological properties were determined after 4 and 8 weeks and at the end of storage for each treatment such as storage period (day), weight loss (g), soluble solids content and titratable acidity).

\section{Statistical analysis}

The data were subjected to statistical analysis by ANOVA using computer software WASP (Web Agri Stat Package). The values presented are the means of all measurements, and comparisons of means were determined by Duncan's multiple range tests, at $P \leq 0.05$ (Gomez and Gomez, 1984).

\section{Results}

Isolation, identification and pathogenicity tests of the fungal pathogens causing rots of pomegranate fruits

Isolation trails which were carried on pomegranate fruits showing different types of rots collected from different locations, i.e. wholesale \& retail markets as well as refrigerators, located at El-Gharbia, Kafr ElSheikh, El-Behira and Alexandria governorates during 2015 season resulted in the isolation of certain fungal pathogens. These fungal pathogens were identified as $B$. cinerea, $P$. expansum, A. alternate, A. niger and $P$. rubrum. Results in Table 1 show the frequency $\%$ of the fungal pathogens isolated from rotted fruits, $B$. cinerea was the most frequently isolated pathogen $(30.6 \%)$, followed by $P$. expansum (22\%), A. alternata (20.9\%) and A. niger (17.3 $\%$ ), whereas $P$. rubrum was the least frequent isolate $(9.2 \%)$.

TABLE 1. Frequency of the fungal pathogens isolated from diseased pomegranate fruits.

\begin{tabular}{l|c}
\hline Isolated pathogens & $\begin{array}{c}\text { Frequency } \\
\text { \% }\end{array}$ \\
\hline Botrytis cinerea & 30.6 \\
Penicillium expansum & 22 \\
Alternaria alternata & 20.9 \\
Aspergillus niger & 17.3 \\
Penicillium rubrum & 9.2 \\
\hline
\end{tabular}

Env. Biodiv. Soil Security Vol.1 (2017)
The virulence of the fungal isolates was tested using "Wonderful" pomegranate fruits by artificial inoculation of healthy mature fruits with each of the isolated fungi yielded similar symptoms as those of naturally diseased fruits after 12 days of inoculation at room temperature $\left(25^{\circ} \mathrm{C}\right)$. Results in Table 2 indicated that $B$. cinerea was the most aggressive pathogen since the whole fruits were completely rotted after 9 days of inoculation, followed by $P$. expansum and $A$. niger, which caused complete fruit rotting after 12 days of inoculation. On the other hand, A. alternata was the least virulent pathogen, since the fruits were completely rotted after 17 days of inoculation.

In vitro evaluation of antifungal activity of plant extracts against $B$. cinerea

Preliminary in vitro antifungal assays were carried out to determine the most effective plant extracts against $B$. cinerea using the radial growth method. It is obvious from the results in Table 3 that Z. officinale, T. vulgaris, C. cassia extracts exhibited higher antifungal activity than those of M. indica, O. majorana and S. mucronata. The results also showed that inhibition percentage of mycelial growth of $B$. cinerea increased with increasing the concentration of different extracts. Different tested extracts varied in their ability to suppress the mycelial growth of $B$. cinerea. The most important point; however, is that extracts of C. cassia, Z. officinale and T. vulgaris completely controlled the mycelial growth of $B$. cinerea at concentration of 20000, 30000 and 40000 ppm, respectively.

Determination of minimum inhibitory concentration (MIC) of C. cassia, T. vulgaris and $Z$. officinale against $B$. cinerea

Serial concentrations of Flu (10 to $100 \mathrm{ppm}$ ) and C.c (10000 to $20000 \mathrm{ppm})$, Z.o (15000 to $25000 \mathrm{ppm})$ and T.v (15000 to $30000 \mathrm{ppm})$ were tested against $B$. cinerea to determine their minimum inhibitory concentration (MIC). According to MIC values (Table 4), B. cinerea was more sensitive to fungicide Flusilazole than C. cassia, Z. officinale and T. vulgaris extracts since it completely inhibited radial mycelial growth of $B$. cinerea at $25 \mathrm{ppm}$ while the inhibition zone reached $60.3 \%$ at $10 \mathrm{ppm}$. On the other hand, C. cassia extract had the strongest antifungal activity compared to $Z$. officinale and T. vulgaris extracts since it exhibited complete inhibition of the radial growth of $B$. cinerea with MIC value (20000). 
TABLE 2. Pathogenicity test of the isolated pathogens on "Wonderful" pomegranate fruits at different times after inoculation.

\begin{tabular}{lccccc}
\hline \multirow{2}{*}{ Pathogens } & \multicolumn{5}{c}{ Pathogenicity test after } \\
\cline { 2 - 6 } & 3 days & 5 days & $\mathbf{7}$ days & 9 days & 12 days \\
\hline Control & 0.0 & 0.0 & 0.0 & 0.0 & 0.0 \\
Botrytis cinerea & 3.6 & 7.1 & 11.4 & Completely rotted & ----- \\
Penicillium expansum & 2.3 & 4.9 & 8.1 & 10.2 & Completely rotted \\
Alternaria alternata & 0.0 & 1.4 & 2.1 & 3.8 & 5.4 \\
Aspergillus niger & 1.8 & 3.4 & 6.3 & 8.1 & Completely rotted \\
\hline
\end{tabular}

- Values are means of three replicates.

TABLE 3. Evaluation of antifungal activity of certain plant extracts against $B$. cinerea.

\begin{tabular}{lccccc}
\hline \multirow{2}{*}{ Extracts } & \multicolumn{5}{c}{ Conc. $(\mathbf{p p m})$} \\
\cline { 2 - 6 } & $\mathbf{1 0 0 0 0}$ & $\mathbf{2 0 0 0 0}$ & $\mathbf{3 0 0 0 0}$ & $\mathbf{4 0 0 0 0}$ & $\mathbf{5 0 0 0 0}$ \\
\hline Cinnamomum cassia & $31.1 \mathrm{a}$ & $100.0 \mathrm{a}$ & $100.0 \mathrm{a}$ & $100.0 \mathrm{a}$ & $100.0 \mathrm{a}$ \\
Zingiber officinale & $31.4 \mathrm{a}$ & $85.5 \mathrm{~b}$ & $100.0 \mathrm{a}$ & $100.0 \mathrm{a}$ & $100.0 \mathrm{a}$ \\
Thymus vulgaris & $22.2 \mathrm{~b}$ & $60.3 \mathrm{c}$ & $100.0 \mathrm{a}$ & $100.0 \mathrm{a}$ & $100.0 \mathrm{a}$ \\
Salix mucronata & $4.0 \mathrm{~d}$ & $8.4 \mathrm{f}$ & $6.9 \mathrm{~d}$ & $9.2 \mathrm{c}$ & $75.8 \mathrm{~b}$ \\
Origanum majorana & $10.3 \mathrm{c}$ & $18.1 \mathrm{e}$ & $41.8 \mathrm{c}$ & $66.2 \mathrm{~b}$ & $100.0 \mathrm{a}$ \\
Mangifera indica & $9.2 \mathrm{c}$ & $44.4 \mathrm{~d}$ & $48.5 \mathrm{~b}$ & $100.0 \mathrm{a}$ & $100.0 \mathrm{a}$ \\
LSD (0.05) & 3.917 & 3.442 & 3.44 & 1.349 & 1.224 \\
\hline
\end{tabular}

- Values are means of three replicates.

- Means values in each column followed by the same letter are not significantly different $(\mathrm{P} \leq 0.05)$.

TABLE 4. Minimum inhibitory concentration (MIC) of C. cassia and Z. officinale and T. vulgaris extracts as well as fungicide Flusilazole against B. cinerea.

\begin{tabular}{|c|c|c|}
\hline Plant extracts & Concentration (ppm) & Inhibition percentage \\
\hline \multirow{5}{*}{ Cinnamomum cassia } & 10000 & 31.1 \\
\hline & 12000 & 46.3 \\
\hline & 15000 & 62.5 \\
\hline & 17000 & 71.1 \\
\hline & 20000 & 100.0 \\
\hline \multirow{4}{*}{ Zingiber officinale } & 15000 & 44.4 \\
\hline & 17000 & 62.5 \\
\hline & 20000 & 85.5 \\
\hline & 25000 & 100.0 \\
\hline \multirow{5}{*}{ Thymus vulgaris } & 15000 & 44.0 \\
\hline & 17000 & 55.2 \\
\hline & 20000 & 60.3 \\
\hline & 25000 & 88.5 \\
\hline & 30000 & 100.0 \\
\hline \multirow{5}{*}{ Flusilazole } & 10 & 60.3 \\
\hline & 25 & 100.0 \\
\hline & 50 & 100.0 \\
\hline & 75 & 100.0 \\
\hline & 100 & 100.0 \\
\hline
\end{tabular}

- Values are means of three replications 
In vitro antifungal potential of combination of the fungicide Flusilazole and plant extracts against B. cinerea

To investigate the ability of C. cassia, T. vulgaris and $Z$. officinale extracts to minimize the use of synthetic fungicide Flusilazole entirely or partially, they were separately mixed with Flusilazole at rates of 1:1, 1:2 and 2:1 for Flusilazole to plant extracts. The results in Table 5 showed that the combination of each plant extract with Flusilazole improved the efficacy against $B$. cinerea compared to that of each plant extract and Flusilazole alone. The most effective combination against $B$. cinerea was C.c+Flu (2:1) followed by C.c+Flu (1:2), C.c+Flu (1:1) and Z.o+Flu $(1: 2)$, while the lowest effective combination was T.v+Flu (1:1) and Z.o+Flu (2:1).

In vitro effect of the used bioagents (B. subtilis and P. fluorescens) against fungal pathogens of pomegranate fruit rots

$B$. subtilis and P. fluorescens were tested against $B$. cinerea, $P$. expansum, A alternata, $A$. niger and $P$. rubrum under laboratory conditions $\left(25-28^{\circ} \mathrm{C}\right)$. The obtained results indicated that B. subtilis and P. fluorescens were antagonistic against the tested pathogenic fungi. It worth to mention that $B$. subtilis and P. fluorescens prevented sporulation of $P$. expansum and $P$. rubrum, while it gave inhibition zone with the other fungi. Results presented in Table 6 showed the relative power of antibiosis of both $B$. subtilis and $P$. fluorescens against the different fungal isolates. From such results, $B$. subtilis was more effective against $P$. expansum, B. cinerea and A. alternata than $P$. fluorescens. Generally, each of those two bacterial bioagents had high antibiosis against all tested pathogens; however, their effect varied from pathogen to another.

Effect of plant extracts and their combinations with Flusilazole or bioagents on pomegranate fruits under cold storage

Storage period

Storage period of pomegranate fruits treated with plant extracts (C. cassia, T. vulgaris and $Z$. officinale), fungicide Flusilazole, combinations between plant extracts and Flusilazole as well as bioagents (B. subtilis and P. fluorescens) under cold storage at $5 \pm 1{ }^{\circ} \mathrm{C}$ and $90 \% \mathrm{RH}$ was studied. Results in Fig. 1 showed that all treatments were effective in prolonging the storage period of pomegranate fruits treated with the aforementioned treatments compared with the control that was totally rotted after 45 days of storage. The mixture C.c+Flu (2:1; v:v) was the best treatment in extending the storage period of pomegranate fruits for 87 days while the least treatments were the plant extract $T$. vulgaris as well as fungicide Flusilazole for 78 days.

\section{Weight loss}

Results in Figs. 2 and 3 illustrated that all tested treatments significantly reduced weight loss than in control after 12 weeks of cold storage at $5 \pm 1{ }^{\circ} \mathrm{C}$ and $95 \% \mathrm{RH}$. Weight loss of pomegranate fruits ranged from $3.6 \%$ to $6.2 \%$ as a result of the used treatments compared to the control $(12.9 \%)$. However, no symptoms of shriveling were observed. The best treatment to reduce weight loss was the mixture C.c+Flu (2:1; $3.6 \%$ ) followed by B.s (4\%). After shelf life for 10 days, the weight loss in pomegranate fruits was highly increased in all treated fruits. It ranged between $7.1 \%$ in C.c+Flu (2:1) and $19.7 \%$ in Flu.

\section{Soluble solids content (SSC)}

Results in Table 7 showed that considerable variation was observed in soluble solids content (SSC) of stored pomegranate fruits for up to 12 weeks in some treatments at $5 \pm 1{ }^{\circ} \mathrm{C}$ and $90 \%$ RH. It increased rapidly during all stages of pomegranate fruits cold storage. At the end of storage, it reached at least $17.3^{\circ}$ Brix in some treatments. SSC increased in "Wonderful" cultivar from 14.3 to $17.3^{\circ}$ Brix during cold storage. There were no significant differences between the treatments and control.

\section{Titratable acidity (TA)}

Titratable acidity (expressed as \% tartaric acid) in pomegranate fruits "Wonderful" cultivar decreased during cold storage for up to 12 weeks in some treatments at $5 \pm 1{ }^{\circ} \mathrm{C}$ and $90 \%$ RH. Results in Table 8 showed that The TA level decreased from $1.5 \%$ to $1.3 \%$. Generally, there were no significant differences between the treatments and control. 
TABLE 5. Antifungal potential of $C$. cassia, Z. officinale, T. vulgaris and fungicide Flusilazole and their combinations against $B$. cinerea.

\begin{tabular}{l|c|c}
\hline Treatments & Concentration (ppm) & Inhibition percentage \\
\hline C.c & 15000 & $62.5 \mathrm{e}$ \\
Z.o & 17000 & $62.5 \mathrm{e}$ \\
T.v & 17000 & $55.2 \mathrm{f}$ \\
Flu & 10 & $60.3 \mathrm{ef}$ \\
C.c + Flu (1:1) & $5: 5$ & $83.7 \mathrm{~b}$ \\
C.c + Flu (1:2) & $3.3: 6.7$ & $86.6 \mathrm{ab}$ \\
C.c + Flu (2:1) & $6.7: 3.3$ & $89.6 \mathrm{a}$ \\
Z.o + Flu (1:1) & $5: 5$ & $77.4 \mathrm{~cd}$ \\
Z.o + Flu (1:2) & $3.3: 6.7$ & $82.2 \mathrm{bc}$ \\
Z.o + Flu (2:1) & $6.7: 3.3$ & $74.0 \mathrm{~d}$ \\
T.v + Flu (1:1) & $5: 5$ & $74.0 \mathrm{~d}$ \\
T.v + Flu (1:2) & $3.3: 6.7$ & $75.6 \mathrm{~d}$ \\
T.v + Flu (2:1) & $6.7: 3.3$ & $77.4 \mathrm{~cd}$ \\
LSD (0.05) & & 5.604 \\
\hline
\end{tabular}

- Values are means of three replicates.

- C.c: C. cassia, Z.o: Z.officinale, T.v: T. vulgaris, Flu: Fludioxonil.

TABLE 6. Relative power of antibiosis (RPA) of bacterial antagonists against the tested fungal pathogens of pomegranate fruit .

\begin{tabular}{lccccc}
\hline \multirow{2}{*}{ Antagonists } & \multicolumn{5}{c}{ Fungal pathogens } \\
\cline { 2 - 6 } & B. cinerea & P. expansum & A. alternata & A. niger & P. rubrum \\
\hline B. subtilis & 2.74 & 3.00 & 2.43 & 2.15 & 2.95 \\
P. fluorescens & 2.50 & 2.36 & 2.25 & 2.00 & 2.20 \\
\hline
\end{tabular}

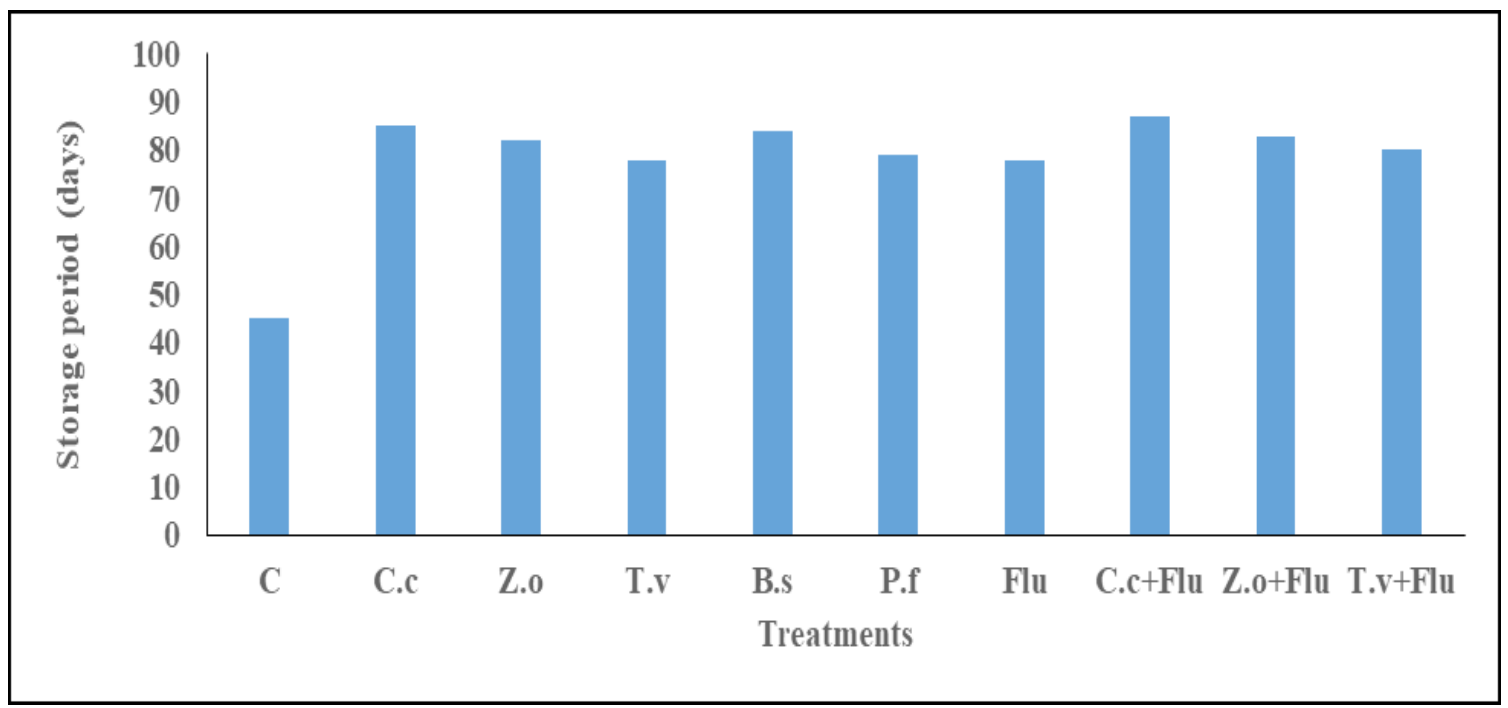

- C: Control, C.c: C. cassia, Z.o: Z.officinale, T.v: T. vulgaris, B.s: B. subtilis, P.f: P. fluorescens, Flu: Fludioxonil.

Fig. 1. Influence of postharvest treatments on storage period of "Wonderful" pomegranates after 12 weeks of cold storage at $5 \pm 1 \mathrm{oC}$ and $90 \% \mathrm{RH}$. 


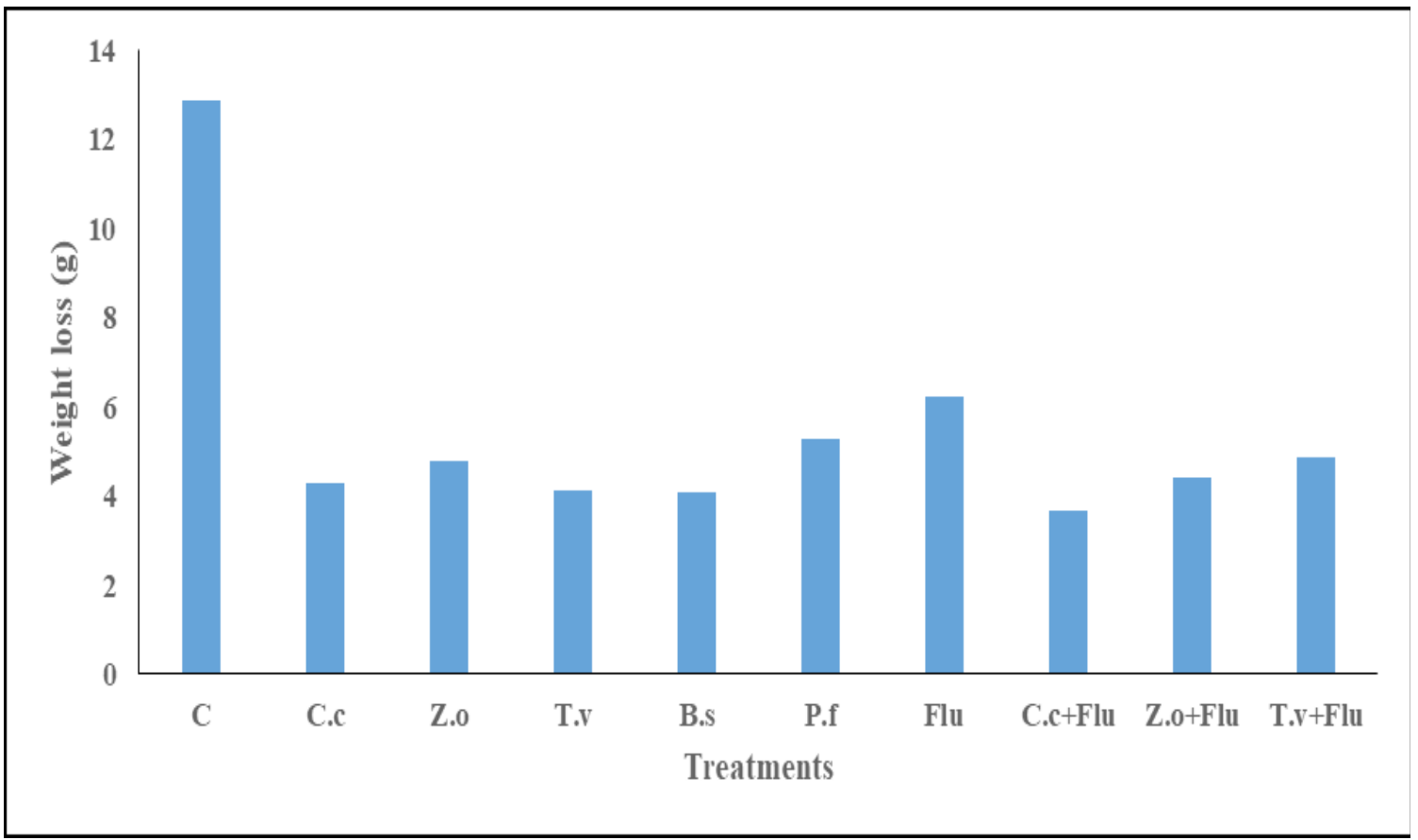

- C: Control, C.c: C. cassia, Z.o: Z.officinale, T.v: T. vulgaris, B.s: B. subtilis, P.f: P. fluorescens, Flu: Fludioxonil.

Fig. 2. Influence of postharvest treatments on the weight loss of "Wonderful" pomegranates after 12 weeks of cold storage at $5 \pm 10 \mathrm{C}$ and $90 \% \mathrm{RH}$.

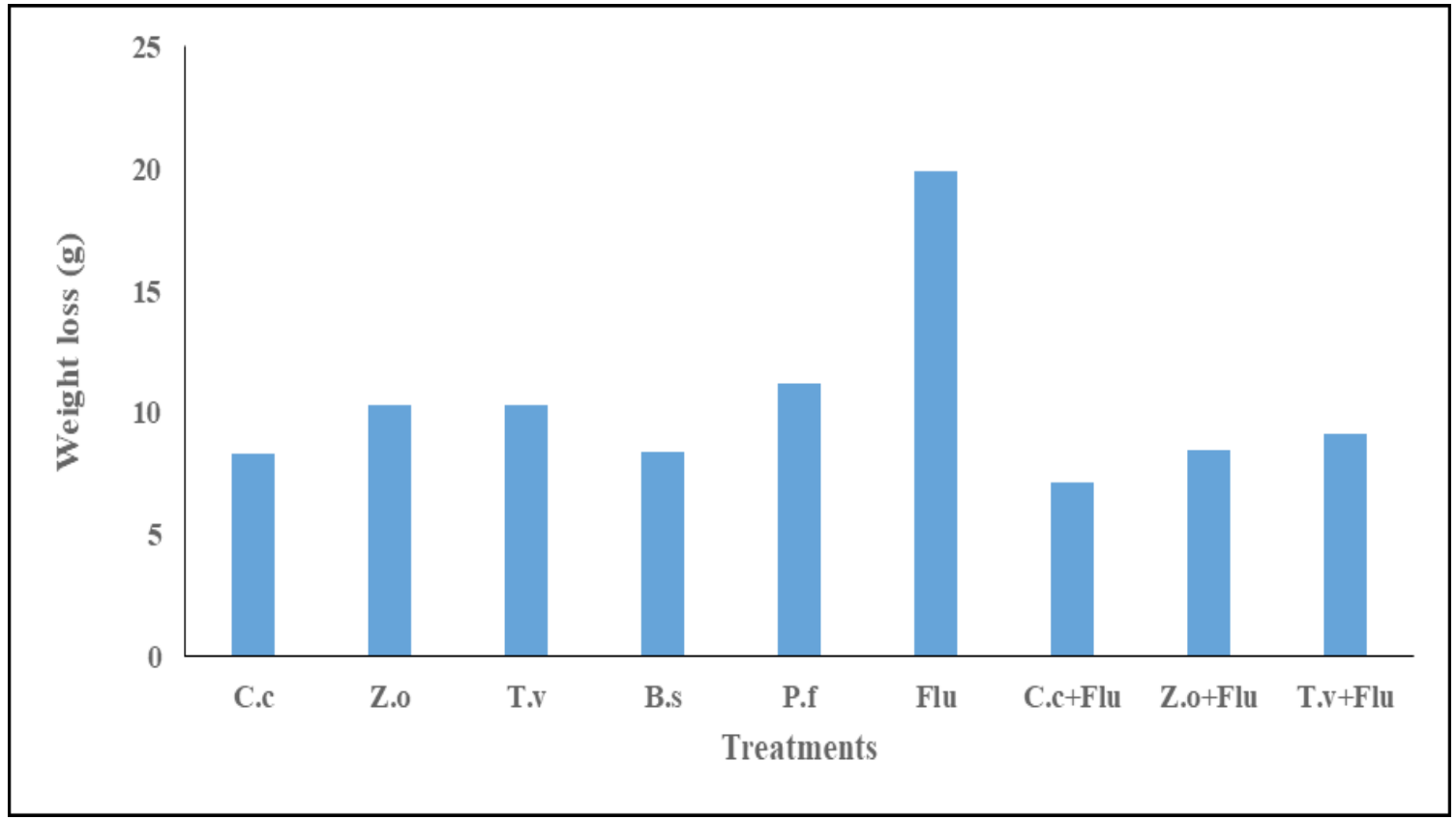

- C.c: C. cassia, Z.o: Z.officinale, T.v: T. vulgaris, B.s: B. subtilis, P.f: P. fluorescens, Flu: Fludioxonil.

Fig. 3. Influence of postharvest treatments on the weight loss of "Wonderful" pomegranates after 10 days of shelf life at $25 \pm 2{ }^{\circ} \mathrm{C}$ and $60 \% \mathrm{RH}$.

Env. Biodiv. Soil Security Vol.1 (2017) 
TABLE 7. Effect of certain treatments on soluble solids content (Brix) of pomegranate fruits during cold storage at $5 \pm 1{ }^{\circ} \mathrm{C}$ and $90 \%$ RH.

\begin{tabular}{|c|c|c|c|c|}
\hline Treatments & Concentration (ppm) & 4 weeks & 8 weeks & End of storage \\
\hline Control & ----- & $16.2 \mathrm{a}$ & ----- & ----- \\
\hline C.c & 15000 & $14.7 \mathrm{def}$ & $15.2 \mathrm{~cd}$ & $15.8 \mathrm{de}$ \\
\hline C.c + Flu & $100: 50$ & $14.3 \mathrm{f}$ & $14.9 \mathrm{~d}$ & $15.5 \mathrm{e}$ \\
\hline Z.o & 17000 & $15.2 \mathrm{bcd}$ & $15.8 \mathrm{~b}$ & $16.3 \mathrm{bcd}$ \\
\hline Z.o + Flu & $100: 50$ & 14.9 cde & $15.5 \mathrm{bc}$ & $16.03 \mathrm{de}$ \\
\hline T.v & 17000 & $15.6 \mathrm{~b}$ & $15.8 \mathrm{~b}$ & $16.8 \mathrm{ab}$ \\
\hline T.v + Flu & $100: 50$ & $14.6 \mathrm{ef}$ & $15.2 \mathrm{~cd}$ & $16.2 \mathrm{bcd}$ \\
\hline B.s & $10^{8} \mathrm{CFU} \mathrm{ml}^{-1}$ & $14.7 \mathrm{def}$ & $15.1 \mathrm{~cd}$ & $15.5 \mathrm{e}$ \\
\hline P.f & $10^{8} \mathrm{CFU} \mathrm{m1^{-1 }}$ & $15.1 \mathrm{bcde}$ & $15.5 \mathrm{bc}$ & $16.1 \mathrm{~cd}$ \\
\hline Flu & 150 & $15.5 \mathrm{bc}$ & $16.03 \mathrm{~b}$ & $16.6 \mathrm{bc}$ \\
\hline $\operatorname{LSD}(0.05)$ & & 0.551 & 0.528 & 0.572 \\
\hline
\end{tabular}

- Values are means of three replicates.

- C.c: C. cassia, Flu: Fludioxonil, Z.o: Z.officinale, T.v: T. vulgaris, B.s: B. subtilis, P.f: P. fluorescens.

- All control fruits were completely rotted after 4 weeks.

TABLE 8. Effect of certain treatments on titratable acidity of pomegranate fruits during cold storage at $5 \pm 1{ }^{\circ} \mathrm{C}$ and $90 \%$ RH.

\begin{tabular}{|c|c|c|c|c|}
\hline Treatments & Concentration (ppm) & 4 weeks & 8 weeks & End of storage \\
\hline Control & ----- & 1.5 & ----- & ----- \\
\hline C.c & 15000 & 1.5 & 1.4 & $1.4 \mathrm{a}$ \\
\hline C.c + Flu & $100: 50$ & 1.5 & 1.4 & $1.3 \mathrm{~b}$ \\
\hline Z.o & 17000 & 1.5 & 1.4 & $1.3 \mathrm{~b}$ \\
\hline Z.o + Flu & $100: 50$ & 1.5 & 1.4 & $1.4 \mathrm{a}$ \\
\hline T.v & 17000 & 1.5 & 1.4 & $1.3 \mathrm{~b}$ \\
\hline T.v + Flu & $100: 50$ & 1.4 & 1.4 & $1.3 \mathrm{~b}$ \\
\hline B.s & $10^{8} 10^{8} \mathrm{CFU} \mathrm{ml}^{-1}$ & 1.4 & 1.4 & $1.3 \mathrm{~b}$ \\
\hline P.f & $10^{8} 10^{8} 10^{8} \mathrm{CFU} \mathrm{ml}^{-1}$ & 1.5 & 1.4 & $1.4 \mathrm{a}$ \\
\hline Flu & 150 & 1.5 & 1.4 & $1.3 \mathrm{~b}$ \\
\hline LSD (0.05) & & N.S & N.S & 0.018 \\
\hline
\end{tabular}

- Values are means of three replicates.

- C.c: C. cassia, Flu: Fludioxonil, Z.o: Z.officinale, T.v: T. vulgaris, B.s: B. subtilis, P.f: P. fluorescens.

- All control fruits were completely rotted after 4 weeks. 


\section{Discussion}

An intensive survey of major postharvest diseases of pomegranate fruits was carried out during 2015 season from different pomegranate orchards, wholesale and retail markets as well as refrigerators, at EL-Gharbia, Kafr El-Sheikh, El-Behira and Alexandria. Obtained results indicated that the occurrence of different types of fruit rots caused by $B$. cinerea, $P$. expansum, A. alternata, A. niger and P. rubrum. Pathogenici ty tests of the isolated fungi from pomegranate fruits revealed that all the aforementioned fungi were pathogenic and caused various degrees of fruit rot symptoms. Many investigators in different countries recorded one or more of those pomegranate fruit diseases and their causal pathogens (Pala et al., 2009). Application of chemical fungicides to protect fruits from the attack of pathogenic fungi was the primary means for controlling fruit rot diseases. In recent years, chemical fungicides have become less effective due to the development of pathogen resistance (Parveen and Dhandapani, 2002), this has necessitated the search for replacement fungicides by alternative non-chemical control methods. Moreover, the reduction of total fungicides application rates is one of the dominant trends in agricultural production. This can be achieved by different ways including the introduction of new or more effective chemicals, the purification of the chemicals and/or the combination of the formulation with plant extracts or culture filtrates of biocontrol agents.

The results showed satisfactory control of fungal rots of pomegranate fruits by dipping them in either cell suspension of $B$. subtilis and P. fluorescens or plant extracts of C. cassia, $Z$. officinale, $T$. vulgaris as well as the combination between the aforementioned plant extracts with fungicide Flusilazole. The results showed that all the aforementioned treatments successfully extended the storage period of pomegranate fruits during cold storage. It is clear from the results that plant extracts of C. cassia, Z. officinale, T. vulgaris exhibited high antifungal activity against fungal rots of pomegranate fruits. This might be due to that, cinnamon bark contains high percentage of cinnamaldehyde (Lopez et al., 2007) or mixture of cinnamaldehyde and eugenol (Ito, 2008) and they are rich in benzyl benzoate (Nath et al., 1996). Khan and Ahmad (2011) reported that cinnamaldehyde showed the most promising antifungal activity and killing potency against Aspergillus fumigates
MTCC2550 and Trichophyton rubrum IOA9. Cinnamaldehyde showed strongest synergy with fluconazole against A. fumigatus and $T$. rubrum. Phytochemical investigation of the rhizomes of several Zingiber spp. has revealed the presence of bioactive compounds, such as gingerols, which are antibacterial agents and shogaols (Kim et al., 2008), diarylheptanoids (Zhou et al., 2007), phenylbutenoids (Jitoe et al., 1993), flavanoids (Dae et al., 2004), diterpenoids and sesquiterpenoids (Dae and Seo, 2005). Singh et al. (2011) also reported that alcoholic extract of $Z$. officinale showed antifungal activity against A. niger and Fusarium sp. isolated from naturally infected citrus fruit. Moreover, combining the fungicide Flusilazole with plant extracts improved the efficacy against fungal pathogens of pomegranate fruit rots. The results of our study demonstrate the potential of using plant extracts in combination with a fungicide to improve the efficiency of the antifungal activity (Derbalah et al., 2012). In decay inhibition studies on Granny Smith apples, synergistic and additive effects were observed for many of the combinations between plant extracts used in that study and fungicide kresoxim-methyl (Fielding et al., 2015).

The in vitro results indicated that the bacterial isolates B. subtilus and P. fluorescens suppressed growth of all the pathogens cultured on PDA medium at laboratory temperature $\left(25-30^{\circ} \mathrm{C}\right)$. The antagonistic activity of $B$. subtilus has been known to be potent producers of many antibiotics, which suppress both bacteria and fungi (Ibrahim et al., 1987; Pusey et al., 1988). However, secondary metabolites of $B$. subtilus have proven to inhibit several plant pathogenic fungi (Asante and Neal, 1964; Burachik et al., 1964). Furthermore, the genus Pseudomonas includes certain species and strains that have been recognized as antibiosis to plant pathogens. Pyrrolnitrin produced by $P$. cepacia controlled gray mold caused by $B$. cinerea and reduced blue mold caused by $P$. expansum on pome fruits at $2-4{ }^{\circ} \mathrm{C}$ (Janisiewick et al., 1991).

The obtained results showed that treatment with bacterial bioagents or plant extracts alone or in combinations with fungicide Flusilazole had significantly decreased weight loss of pomegranate fruits. Weight loss is considered a major cause of loss of visual quality of horticultural products: excessive transpiration can lead to desiccation, wilting, shriveling, reduced crispness and firmness, and hasten senescence by lowering the endogenous level of plant growth regulators and 
increasing those leading to ageing (Ben-Yehoshua and Rodov, 2003). Artes and Tomés-Barberén (2000) considered relative humidity the second most important factor (after storage temperature) affecting pomegranate quality, while exceeding a $5 \%$ weight loss was indicated as the threshold for visible shriveling symptoms (Palou et al., 2007). Loss of weight in stored pomegranate fruits is mainly due to evaporation of water from the fruit and becomes apparent as shriveling (Barman et al., 2011). Pomegranate is highly susceptible to weight loss due to the high porosity of the fruit peel, which permits free water vapor movement (Kader et al., 1984).

\section{Conclusion}

In conclusion, combinations between extracts of $C$. cassia, Z. officinale and T. vulgaris with the fungicide Flusilazole or the cell suspension of $B$. subtilis and $P$. fluorescens effectively inhibited the fungal growth of $B$. cinerea in vitro and also prolonged the storage period of pomegranate fruits for up to 12 weeks during cold storage at $5 \pm 1{ }^{\circ} \mathrm{C}$ and $90 \% \mathrm{RH}$.

\section{$\underline{\text { References }}$}

Artes, F. and Tomés-Barberén, F.A. (2000) Postharvest technological treatments of pomegranate and preparation of derived products, Production, Processing and Marketing of Pomegranate in the Mediterranean Region: Advances in Research and Technology. pp. 199-204.

Asante, G.S. and Neal, A.L. (1964) Characterization of fungistatic substances produced by Bacillus antagonistic to Ceratocystis ulmi. Phytopathol., 54, 819 .

Barman, K., Asrey, R. and Pal, R.K. (2011) Putrescine and carnauba wax pretreatments alleviate chilling injury, enhance shelf life and preserve pomegranate fruit quality during cold storage. Sci. Hortic., 130,795-800?

Ben-Yehoshua, S. and Rodov, V. (2003) Transpiration and water stress. Post. Physiol. Pathol, Vegetables, 2, 111-159.

Brown, W. (1924)Two mycelial methods. II. A method of isolation single strains on fungi by cutting out a hyphal tip. Ann. Botany, 38, 401-404.

Burachik, M., Leardini, N.A. and Paladini, A.C. (1964) Three antifungal polypeptides from Bacillus subtilis. Experientia, 20, 504-505.

Dae, S.J., Han, A.R., Park, G., Jhon, G.J. and Seo, E.K. (2004) Flavonoids and aromatic compounds from the rhizomes of Zingiber zerumbet. Arch. Pharmacal Res., 27, 386-389.

Dae, S.J. and Seo, E.K. (2005) Potentially bioactive two new natural sesquiterpenoids from the rhizomes of Zingiber zerumbet. Arch. Pharmacal Res., 28, 294296.

Derbalah, A.S., Elkot, G.A.E. and Hamza, A.M. (2012) Laboratory evaluation of botanical extracts, microbial culture filtrates and silver nanoparticles against Botrytis cinerea. Ann. Microbiol., 62, 13311337.

El-Arosi, H. (1960) Gloeosporium fruit rot of banana. Trans. Br. Mycol. Soc., 43, 681-687.

El-Kot, G.A.N. and Hegazi, M.A. (2008) Nonchemical control of powdery mildew disease on zinnia (Zinnia elegans, L.). Alex. J. Agric. Res., 53, 219-230.

El-Qurashi, M.A., El-Zawahry, A.M., Abd-ElMoneem, K.M.H. and Hassan, M.I. (2017) Morphological and molecular identification of root-knot nematodes infecting pomegranate in Assiut Governorate, Egypt. J. Phytopathol. Pest Manage., 4, 30-37.

Fielding, B.C., Knowles, C.L., Vries, F.A. and Klaasen, J.A. (2015) Testing of eight medicinal plant extracts in combination with KresoximMethyl for integrated control of Botrytis cinerea in apples. Agric., 5, 400-411.

Gomez, K.A. and Gomez, A.A. (1984) Statistical Procedures for Agricultural Research. Wiley, New York, USA.

Hansen, H.N. (1926) A simple method of obtaining single-spore cultures. Science, 64, 384.

Ibrahim, M.E.K., Mehiar, F.F. and El-Gremi, S.M. (1987) Biological control of black leg, soft rot and common scab of potato by bacterial antagonists. J. Agric. Res. Tanta Univ., 13, 1-15.

Ito, M. (2008) Studies on perilla, agarwood, and cinnamon through a combination of fieldwork and laboratory work. J. Nat. Med., 62, 387-395.

Janisiewicz, W., Yourman, L., Roitman, J. and Mahoney, N. (1991) Postharvest control of blue mold and gray mold of apples and pears dip treatment with pyrrolnitrin, a metabolite of Pseudomonas cepacia. Plant Dis., 75, 490-494.

Jitoe, A., Masuda, T. and Nakatani, N. (1993). Phenylbutenoids from the rhizomes of Zingiber

Env. Biodiv. Soil Security Vol.1 (2017) 
cassumunar. Phytochem., 32, 357-363.

Kader, A., Chordas, A. and Elyatem, S. (1984) Responses of pomegranates to ethylene treatment and storage temperature. California Agric., 38, 1415 .

Khan, M.S.A. and Ahmad, I. (2011) Antifungal activity of essential oils and their synergy with fluconazole against drug-resistant strains of Aspergillus fumigatus and Trichophyton rubrum. App. Microbiol. Biotechnol., 90,1083-1094.]

Kim, J.S., Lee, S.I., Park, H.W., Yang, J.H., Shin, T.Y. and Kim, Y. C. (2008). Cytotoxic components from the dried rhizomes of Zingiber officinale Roscoe. Arch. Pharmacal Res., 31, 415-418.

Latha, P., Anand, T., Ragupathi, N., Prakasam, V., and Samiyappan, R. (2009) Antimicrobial activity of plant extracts and induction of systemic resistance in tomato plants by mixtures of PGPR strains and zimmu leaf extract against Alternaria solani. Biol. Control, 50, 85-93.

Lopez, P., Sanchez, C., Batlle, R., and Nerín, C. (2007) Vapor-phase activities of cinnamon, thyme, and oregano essential oils and key constituents against food borne microorganisms. J. Agric. Food Chem., 55, 4348-4356.

Mars, M. (2000) Pomegranate plant material: Genetic resources and breeding, a review. In: Melgarejo P. (ed.), Martínez-Nicolás J.J. (ed.), Martínez-Tomé J. (ed.). Production, processing and marketing of pomegranate in the Mediterranean region: Advances in research and technology. Zaragoza: CIHEAM, pp. 55-62.

Moline, H.E. and Locke, J.C. (1993) Comparing neem seed oil with calcium chloride and fungicides for controlling post-harvest apple decay. Hortic. Sci., 28, 719-720.

Mujica, M.V., Granito, M. and Soto, N. (2009) Importance of the extraction method in the quantification of total phenolic compounds in Phaseolus vulgaris L. Interciencia, 34, 650-654.

Nath, S.C., Pathak, M.G. and Barua, A. (1996) Benzyl benzoate, the major component of the leaf and stem bark oil of Cinnamomum zeylanicum Blume. J. Essent. Oil Res., 8, 327-328.

Ozcelik, N. and Ozcelik, S. (1997)Investigations on some factors and strains affecting the production of Alternaria-toxins by a thin layer chromatographic method. Turk. J. Agric. For., 21, 1-5.

Env. Biodiv. Soil Security Vol.1 (2017)
Pala, H., Tatli, A., Yilmaz, C., and Özgüven, A.I. (2006) Important diseases of pomegranate fruit and control possibilities in Turkey. In: International Symposium on Pomegranate and Minor Mediterranean Fruits, 818, 285-290?

Palou, L. and Del Rio, M.A. (2007) Assessment of fungal pathogens causing postharvest decay of pomegranate in southeast Spain. In: $1^{\text {st }}$ International Symposium on Pomegranate and Minor Mediterranean Fruits, 818, 305-312.

Palou, L., Crisosto, C.H. and Garner, D. (2007) Combination of postharvest antifungal chemical treatments and controlled atmosphere storage to control gray mold and improve storability of 'Wonderful' pomegranates. Post. Biol. Technol., 43, 133-142.?

Parveen, P.M. and Dhandapani, N. (2002) Eco-friendly management of major pests okra (Abelmoschus esculentus L.). J. Vegetable Crop Prod., 7, 3-11.

Pusey, P.L., Hotchkiss, M.W., Dulmage, H.T., Baumgardner, R.A., Zehr, E.I., Reilly, C.C. and Wilson, C.L. (1988) Pilot tests for commercial production and application of Bacillus subtilis (B3 ) for postharvest control of peach brown rot. Plant Dis., 72, 622-626.

Singh, H., Fairs, G. and Syarhabil, M. (2011) Antifungal activity of Capsicum frutescence and Zingiber officinale against key post-harvest pathogens in citrus. In: International Conference on Biomedical Engineering and Technology, 11.]

Teksur, P.K., Şen, F. and Yıldız, F. (2014) The Prevention of Fungal Decays and Improving Fruit Quality with Some Pre and Postharvest Treatments on Pomegranate Fruit. Stewart Postharvest Review, $158 \mathrm{pp}$.

Thomidis, T. (2014) Fruit rots of pomegranate (cv. Wonderful) in Greece. Australasian Plant Pathol., 43, 583-588.

Wu, Z., Yin, X., Bañuelos, G.S., Lin, Z.Q., Zhu, Z., Liu, Y., Yuan, L. and Li, M. (2016) Effect of selenium on control of postharvest gray mold of tomato fruit and the possible mechanisms involved. Front. Microbiol., 6 (1441), 1-11.

Zhou, C.X., Zhang, X.Y., Dong, X.W., Tao, Q.F., Dou, H. and Zhang, R.P. (2007) Three new diarylheptanoids and their antioxidant property. Chin. Chem. Lett., 18, 1243-1246.

(Received 11/10/2017; accepted 2/11/2017) 